\title{
Uzun Süre Hastanede Yatan Hastalarda Clostridium difficile Kolonizasyonunun Araştırılması
}

\section{An Investigation of Clostridium difficile Colonization in Patients with Prolonged Hospitalization}

\section{Öz}

Amaç: Clostridium difficile antibiyotik ile ilişkili ishal ve kolitlerin en önemli nedenidir. Dünyada önemli bir sağlık sorunu olan antibiyotik ile ilişkili ishal olgularının \%15-30'undan sorumlu tutulmaktadır. Clostridium difficile enfeksiyonu hafif ishalden toksik megakolon oluşumuna kadar varan, değişken bir klinik tablo sergilemektedir ileri yaş, hastanede yatma ve özgün antibiyotiklere maruz kalma Clostridium difficile enfeksiyonu için en yaygın risk faktörleridir. Bu çalışmada uzun süre hastanede yatan hastalarda Clostridium diffıcile toksin A/B varlığı araştırılmıştı; bu tür bir araştırma bölgemizde daha önce hiç yapılmamıştır.

Gereç ve Yöntemler. Bu çalışma 1 Temmuz 2015 - 30 Eylül 2015 tarihleri arasında, Düzce Üniversitesi Sağlık Araştırma ve Uygulama Hastanesi'nde yapılmıştır. Yatarak tedavi gören, hastanede yatış süresi $\geq 72$ saat olan 77 hasta çalışmaya dahil edilmiştir. Bu hastalarda enfeksiyon ya da kolonizasyon gelişiminde etkili olan risk faktörleri prospektif olarak sorgulanarak kaydedilmiştir. Çalışmaya alınan hastaların gaita örneklerinde Clostridium difficile toksin A/B varlığı ELISA yöntemi ile araştırılmıştır. Bulgular SPSS v.22 paket programı ile analiz edilmiştir.

Bulgular. 77 hastaya ait 104 örneğin yalnızca üçü $(\% 2,8)$ Clostridium difficile toksin A/B pozitif bulunmuştur. Pozitif bulunan üç hastada ortak özellik olarak, en az beş gündür yatarak tedavi görülmüş olması, altta yatan hastalıkların bulunması, ve antibiyotik ve proton pompa inhibitörü türü ilaç kullanımı dikkat çekmiştir.

Tartışma ve Sonuç: Sonuçlarımız, hastanemizden ve bölgemizden bildirilen ilk veriler olması yönünden önemlidir. Çalışmamızda \%2,8 olarak saptanan Clostridium diffıcile kolonizasyon oranı düşük olarak değerlendirilmiş ancak daha önce bölgemizde bu konuda yapılmış bir çalışmaya ulaşılamadığından karşılaştırma imkanı olmamıştır. Bu konuda farklı yöntemler kullanılarak, geniş örneklem grupları oluşturularak, çok merkezli çalışmalar yapılmasının faydalı olacağı düşünülmüştür.

Anahtar Sözcükler. Clostridium diffıcile; toksin A/B; risk faktörleri; psödomembranöz enterokolit (PMC).

\section{Abstract}

Aim: Clostridium difficile is the major cause of antibiotic-associated diarrhea and colitis. It is responsible for $15-30 \%$ of cases of antibiotic-associated diarrhea, an important health problem around the world. C. difficile infection manifests in clinical conditions varying from mild diarrhea to toxic megacolon formation. Advanced age, hospitalization, and exposure to mature antibiotics are the most common risk factors for Clostridium difficile infection. In this study, we investigated presence of $C$. difficile toxin $A / B$ in patients with prolonged hospitalization. No similar study was performed in our locality previously.

Materials and Methods: This study was conducted at Düzce University Health Research and Application Hospital between 1 July 2015 and 30 September 2015. Seventy-seven inpatients who had been hospitalized for $\geq 72$ hours were included in the study. Risk factors leading to Clostridium difficile infection or colonization in these patients were recorded through a prospective investigation. Stool samples from the patients were examined by the ELISA method for the presence of Clostridium difficile toxin A/B. The findings were analyzed by using the SPSS (v. 22) software package.

Results: Only three of the 104 samples (2.8\%) from the 77 patients were found Clostridium difficile toxin A/B positive. The common characteristics observed in the three toxin-positive patients were hospitalization for at least five days, presence of underlying diseases, and use of antibiotics and proton pump inhibitors.

Discussion and Conclusion: Our findings are important for being the first relevant data reported in our hospital and locality. The Clostridium difficile colonization rate, which was found to be $2.8 \%$ in our study, was evaluated as low, but no comparison could be made due to the lack of former data. Investigations and multicenter studies to be conducted by using different methods and larger samples would be beneficial.

Keywords: Clostridium difficile; toxin A/B; risk factors; pseudomembranous enterocolitis (PMC)
Şükrü Öksüz1 , Ayşe Danış², Elif Öztürk'', Emel Çalışkan', Nida Kılıç Akar ${ }^{1}$, Mehmet Ali Sungur ${ }^{3}$

Düzce Üniversitesi Tıp Fakültesi Tıbbi Mikrobiyoloji Anabilim Dalı, Konuralp Düzce Türkiye

2 Düzce Üniversitesi Araştırma ve Uygulama Hastanesi Enfeksiyon Kontrol Komitesi, Konuralp Düzce Türkiye

${ }^{3}$ Düzce Üniversitesi Tıp Fakültesi Biyoistatistik ve Tıbbi Bilişim Anabilim Dalı, Konuralp Düzce Türkiye
Geliş Tarihi /Received : 20.03.2017 Kabul Tarihi /Accepted: 19.04.2017

DOI: 10.21673/anadoluklin.298926

Sorumlu Yazar/Corresponding Author Prof. Dr. Şükrü Öksüz

Düzce Üniversitesi Tıp Fakültesi Tıbbi Mikrobiyoloji Anabilim Dall, Konuralp-Düzce

E-mail:droksuz@gmail.com 


\section{GiRiş}

Clostridium difficile yüksek gelirli ülkelerde toksijenik nozokomiyal ishalin en önemli etkenidir. Clostridium difficile gram-pozitif, subterminal yerleşimli sporlu basildir. Clostridium difficile ile ilişkili hastalığın ana virülans faktörleri toksin A ve toksin B'dir.

Clostridium difficile basit bir ishal tablosundan hayatı tehdit eden kolit tablosuna kadar geniş bir hastalık spektrumunda karşımıza çıkar. Sağlıklı erişkinlerde herhangi bir probleme yol açmadan bağırsakta normal florada az sayıda bulunur. Tedavi amacı ile kullanılan antibiyotikler, sitostatik ilaçlar, radyasyon ve bağırsakların cerrahi işlem öncesi mekanik temizliği gibi hastalara uygulanan invaziv işlemler, kolon florasını bozarak çevrede yaygin olarak bulunan Clostridium difficile sporlarının yerleşmesine zemin hazırlamaktadır (1-3).

Antibiyotikle ilişkili ishallerin \%20-30'u, kolitlerin \%50-75'i, psödomembranöz enterokolitlerin (PMC) ise \%90'dan fazlası Clostridium difficile etkeninden ileri gelir. PMC’nin eşlik ettiği ciddi hastalık durumlarında mortalite \%10-15'tir. Clostridium difficile enfeksiyonu ayrıca hasta başına fazladan 2.000-5.000 dolar maliyete yol açarken, aynı zamanda hastanede kalış süresini 18-30 gün uzatmaktadır (4).

$\mathrm{Bu}$ çalışmada, hastanede yatarak tedavi gören ve yatış süresi $\geq 72$ saat olan hastalarda Clostridium difficile varlı̆̆ı, ELİSA yöntemiyle risk faktörleriyle birlikte araştırılmıştır.

\section{GEREÇ VE YÖNTEMLER}

\section{Hastaların Seçimi}

Bu çalışma, 1 Temmuz 2015 - 30 Eylül 2015 tarihleri arasında, Düzce Üniversitesi Sağlık Araştırma ve Uygulama Hastanesi'nde yapılmıştır. Hastanede yoğun bakım üniteleri, dahili klinikler ve cerrahi kliniklerde yatarak tedavi gören ve yatı̧s süresi $\geq 72$ saat olan erişkin hastalar prospektif olarak çalışmaya alınmıştır. Hastalara ait ilk gaita örnekleri, yatışlarından 72 saat sonra alınmıştır. Hastalardan; yatışlarından itibaren birinci hafta (3.-7. günler arası), ikinci hafta (8.-14. günler arası), üçüncü hafta (15.-21. günler arası), dördüncü hafta (22.-28. günler arası) ve beşinci hafta (28. gün ve sonrası) gaita örnekleri alınmıştır. Örnekler ça- lış1ıncaya kadar $-20^{\circ} \mathrm{C}$ 'de saklanmıştır.

\section{Epidemiyolojik Veriler}

Çalışmaya dahil edilen hastaların adı-soyadı, yaşı, cinsiyeti, yaşadığı yer (merkez, ilçe, köy), yatış tanısı, altta yatan hastalıkları, yatış süresi, örnek alma haftası, antibiyotik tedavisi alıp almadığı, alıyorsa antibiyotiğin özelliği ve kaçıncı günü olduğu, kanser tedavisi görüp görmediği, üremi bulgusu, nazogastrik ve/veya endotrakeal tüp varlığı, gastrointestinal sistem operasyonu geçirip geçirmediği, mide koruyucu tedavi görüp görmediği ve görüyorsa tedavinin türü sorgulanmış ve elde edilen veriler Microsoft Office Excel programına kaydedilmiștir.

\section{Çalışma Yöntemi}

Gaita örneklerinden Clostridium difficile A ve B toksinlerinin kantitatif olarak araştırılması için R-Biopharm AG, RIDASCREEN (Darmstadt, Almanya) ticari marka, Clostridium difficile Toxin A/B ELİSA kiti kullanılmış ve üretici firmanın önerileri doğrultusunda çalışma yapılmıştır.

\section{İstatistiksel Analiz}

Çalışmanın istatistiksel analizinde SPSS v.22 paket programı kullanılarak tanımlayıcı istatistikler hesaplanmıştır. Sürekli veriler ortalama \pm standart sapma, kategorik veriler frekans ve yüzde şeklinde özetlenmiştir. Çalışmaya başlamadan önce Düzce Üniversitesi Tip Fakültesi Etik Kurulu'ndan 17.02.2015 tarih ve 2014/118 sayı ile bilgilendirilmiş onam formunu da içeren etik kurul onayı alınmıştır.

\section{BULGULAR}

Araştırmaya alınan 77 (37 erkek, 40 kadın) hastanın yaş ortalaması $68,9 \pm 15,5$ idi. Hastaların hastanede ortalama yatış sürelerinin 12 (4-240) gün olduğu, 59'unun yoğun bakımda, 36'sının dahili servislerde, 9'unun ise cerrahi kliniklerde yattığ saptandı. Araştırmamızda en sık kaydedilen yatı̧s nedeninin kronik kalp hastalığı olduğu görüldü. Çalışmaya alınan hastaların altta yatan hastalıklarının dağılımı Tablo 1'de gösterilmiştir.

Çalışmaya dahil edilen hastaların Clostridium difficile açısından risk faktörlerinin dağılımı Tablo 2'de gösterilmiştir. 
Tablo 1. Çalışmaya alınan hastaların altta yatan hastalıklarının dağılımı

\begin{tabular}{l|c|c}
\hline Hastalı & $\mathbf{n = 7 7}$ & $\%$ \\
\hline Kronik kalp hastalı̆̆ı & 32 & 41,6 \\
\hline Serebrovasküler hastalık & 9 & 11,7 \\
\hline Kronik akciğer hastalığı & 9 & 11,7 \\
\hline Malignite & 7 & 9,1 \\
\hline Kronik böbrek hastalığı & 7 & 9,1 \\
\hline Yok & 7 & 9,1 \\
\hline DM & 2 & 2,6 \\
\hline Enfeksiyon & 2 & 2,6 \\
\hline Alzheimer/Parkinson & 1 & 1,3 \\
\hline Gebe & 1 & 1,3 \\
\hline
\end{tabular}

Çalışmaya alınan 77 hastaya ait 104 numuneden yalnızca üç farklı hastaya ait gaita örneğinde Clostridium difficile toksin A/B pozitif sonuç saptanmış ve bu hastalara ait özellikler Tablo 3 'te gösterilmiştir. Clostridium difficile toksin $\mathrm{A} / \mathrm{B}$ pozitif saptanan üç hastanın da proton pompa inhibitörü ilaç kullandığı belirlenmiştir.

\section{TARTIŞMA VE SONUÇ}

Clostridium difficile mikrobiyolojik tanısı ve epidemiyolojik özellikleri çok iyi tanımlanmış olmasına rağmen ülkemizdeki görece düşük sıklık nedeniyle yeterli veri birikimi sağlanamamıştır. Araştırmamızda yatan hastalarda Clostridium difficile kolonizasyonu sıklığı \%2,8 olarak bulunmuş ve antibiyotik kullanımı, kronik hastalıklar ve uzun süre hastanede yatma gibi etkenlerin kolonizasyon riskini artırmış olabileceği belirlenmiştir.

Clostridium difficile enfeksiyonlarında çoğu zaman kaynak, Clostridium difficile ile enfekte hasta ve çevresidir. Sağlıklı kişilerde Clostridium difficile taşıyıcılık oranı $\% 3$ civarında iken, hastanede yatan, antibiyotik kullanan kişilerde taşıyıcılık oranının \%40'lara ulaştığ 1 bildirilmektedir (8). Mikroorganizma ve sporları tuvaletlerde, telefonlarda, stetoskoplarda, banyo zeminlerinde ve hasta bakımıyla uğraşan sağlık çalışanlarının ellerinde izole edilmiştir. Enfeksiyonun gelişmesinde önemli risk faktörlerinden biri de kolonize ya da enfekte olmayan kişilerin hasta ile aynı odayı paylaşmasıdır. Böylece hastadan hastaya veya çevreden hastaya çapraz bulaş yoluyla enfeksiyon gelişebilmektedir.
Garcia ve ark. nozokomiyal ishalli hastaların \%35,2'sinde Clostridium difficile ile ilişkili ishal tespit etmiş ve Clostridium difficile enfeksiyonlarının hastane ortamında sık yayıldığını göstermiștir (9).

Clostridium difficile toksinini belirlemede altın standart olarak kabul edilen yöntem duyarlılı̆g 1 ve özgüllüğü yüksek olan sitotoksik testlerdir. Ancak bu testlerin pahalı olması, yanı sıra hücre kültür olanakları, fekal filtrat için 24-48 saat gibi uzun bir inkübasyon süresi ve tecrübeli bir personel gerektirmesi gibi dezavantajlar nedeniyle, pek çok laboratuvarda Clostridium difficile toksin $\mathrm{A} / \mathrm{B}$ tespitinde yaygin olarak ELİSA yöntemi kullanılmaktadır. Tunçcan ve ark. 2008'de Gazi Üniversitesi Tip Fakültesi Hastanesi’nde 74'ü nötropenik ve 75 'i non-nötropenik toplam 149 hastada Clostridium difficile toksin A/B pozitiflik oranını sırasıyla $\% 24,3$ ve $\% 21,3$ olarak belirlemiştir (10). Deniz ve ark. ise 2011'de Marmara Üniversitesi Hastanesi'nde yatan 633 hastanın dişkı örneklerinde toksin pozitiflik oranını enzim immünoassay testiyle $\% 4,7$ olarak bildirmiştir (11).

Ju Lin ve ark. Clostridium difficile varlığını araştırdıkları çalıșmalarında toksijenik Clostridium difficile oranını \%17,8 olarak saptamıştır. Yine aynı çalışmada kolonizasyondan ishale geçiş süresi 55,6 gün olarak hesaplanmıştır (12). Bizim çalışmamızda Clostridium difficile toksin A/B pozitiflik oranı ELİSA yöntemiyle \%3,8 olarak tespit edilmiştir. Çalışmamızda saptadığımiz oranlar literatürle uyumlu bulunmuştur.

Clostridium difficile etkenli ishalin oluşmasına neden olan antibiyotik kullanımı dışındaki risk faktörleri ise ileri yaş, hastanede yatma ve altta yatan ciddi bir hastalığın varlığıdır. (10). Yaşlı, altta yatan hastalığ 1

Tablo 2. Risk faktörlerinin dağılımı

\begin{tabular}{l|c|c}
\hline Risk Faktörleri & $\mathbf{n}=77$ & $\%$ \\
\hline Antibiyotik kullanımı & 77 & 100 \\
\hline PPİ kullanımı & 77 & 100 \\
\hline $\mathbf{6 5}$ yaş üstünde olma & 50 & 64,9 \\
\hline NGT/ ETT** & 35 & 45,5 \\
\hline Üremi varlı̆̆ı & 20 & 26 \\
\hline Kanser varlı̆̆ı & 9 & 11,7 \\
\hline GÍS operasyonu geçirmiş olmak & 4 & 5,2 \\
\hline * PPİ: Proton pompa inhibitörü \\
** NGT/ ETT: Nazogastrik tüp / Endotrakeal tüp
\end{tabular}


Tablo 3. Clostridium difficile toksin A/B pozitif saptanan hastaların epidemiyolojik özellikleri

\begin{tabular}{|c|c|c|c|}
\hline Özellik & 1. HASTA & 2. HASTA & 3. HASTA \\
\hline Yaşadığı yer & Şehir Merkezi & Şehir Merkezi & Köy \\
\hline Yaş/Cinsiyet & $60 / \mathrm{K}$ & $72 / \mathrm{E}$ & $68 / \mathrm{E}$ \\
\hline Örnek alınan gün & 60. gün & 30. gün & 5. gün \\
\hline Yatış tanısı & Morbid obezite & $\mathrm{SVO}^{*}$ & Anemi \\
\hline Altta yatan hastalığı/hastalıkları & Hipertansiyon, kalp yetmezliği & Koroner arter hastalığı & $\mathrm{KOAH}^{* *}$ \\
\hline Yattığı klinik & Genel cerrahi & Cerrahi yoğun bakım ünitesi & Dahiliye \\
\hline 65 yaş ve üstï & Hayır & Evet & Evet \\
\hline Antibiyotik tedavisi & Evet & Evet & Evet \\
\hline Kullanılan antibiyotik türü & Meropenem & Meropenem & Seftriakson \\
\hline Nazogastrik tüp takılması & Evet & Evet & Hayır \\
\hline Endotrakeal tïp takılması & Hayır & Evet & Hayır \\
\hline GİS operasyonu geçirme hikayesi & Evet & Hayır & Hayır \\
\hline PPI $\dot{I}^{\star * \star}$ kullanımı & Evet & Evet & Evet \\
\hline
\end{tabular}

olan ve hastaneye yatan bir hasta antibiyotik de alıyorsa Clostridium difficile ile ilişkili hastalık gelişme olasılığı sekiz kat daha fazladır. Yoğun bakımda yatan, cerrahi işlem -özellikle abdominal cerrahi- uygulanmış hastalar, yanık ünitesi ve onkolojide yatan hastalar, Clostridium difficile enfeksiyonu/kolonizasyonu için en fazla risk altında olan diğer hastalardır. Kronik hastalığı olanların daha sık ve daha uzun süre hastanede yatmaları sebebiyle Clostridium difficile ile kolonize olma ihtimali artmaktadır (13). Ercis ve ark. Clostridium difficile toksin $\mathrm{A} / \mathrm{B}$ pozitif tespit ettikleri hastaların \%52,9'unda altta yatan bir hastalık olduğunu, bunların da kronik obstrüktif akciğer hastalığı (KOAH), böbrek yetmezliği ve kanser olarak belirlendiğini bildirmiştir (14). Altuğlu ve ark. ise toksin A pozitif bulunan hastaların operasyon geçirme, politravma, vaskülit, solid tümör, organik fosfat zehirlenmesi, beyin içi kanaması, KOAH gibi nedenlerden dolayı yoğun bakımda yatmakta olduklarını tespit etmiştir (15). Loo ve ark. hasta bakımı ve Clostridium difficile kolonizasyonu arasındaki ilişkiyi araştırdıkları çalışmalarında, yaş ortalaması $63,3 \pm 14,7$ olan ve antibiyotik kullanma, kemoterapi görme, proton pompa inhibitörü, H2 reseptör blokeri, glukokortikoit ve nonsteroid antienflamatuvar ilaç kullanma veya nazogastrik tüp uygulanma durumu bulunan 123 hastanın \%2,5'inde yedi günde kolonizasyon geliştiğini bildirmiştir (16). Nissle ve ark. geriyatrik hastalarda asemptomatik Clostridium difficile taşıyıcılığı, risk faktörleri ve prevalansını araştırdıkları çalışmalarında, Clostridium difficile enfeksiyonu geliştiren hastaların çoğunun kolonize olduğunu (\%87,5) bildirmiştir (17). Çalışmamızda da Clostridium difficile toksin A/B pozitif çıkan üç hastanın genel özellikleri incelendiğinde, birinci hastanın 68 yaşında erkek olduğu, dahiliye kliniğinde anemi ön tanısı ile yatarak tedavi gördüğü, altta yatan $\mathrm{KOAH}$ olduğu, yatışından beri sefalosporin grubu (seftriakson) antibiyotik ve mide koruyucu ilaç tedavisi ald1$\breve{g} 1$ tespit edilmiştir. İkinci hastanın 60 yaşında kadın olduğu, morbid obezite tanısı ile genel cerrahi kliniğinde yattığı, gastrointestinal sisteme yönelik cerrahi girişim geçirdiği, altta yatan hipertansiyon ve solunum yetmezliği hastalıkları olduğu, yatışı esnasında nazogastrik tüp takıldığı, karbapenem grubu (meropenem) antibiyotik ve proton pompa inhibitörü tedavisi aldığ belirlenmiştir. Üçüncü hastanın ise 72 yaşında erkek olduğu, anestezi ve reanimasyon ünitesinde hemorajik serebrovasküler olay tanısı ile yattığı, altta koroner arter hastalığının olduğu, tedavi süresince nazogastrik tüp ve endotrakeal tüp işlemleri uygulandığı, yatışı boyunca antibiyotik ve proton pompa inhibitörü tedavisi aldığı belirlenmiștir. Clostridium difficile toksin A/B 
pozitif saptadığımız hastaların genel özellikleri literatürdeki diğer çalışmalarla benzer bulunmuş, pozitif hastalarla negatif hastalar arasında epidemiyolojik özellikler açısından istatistiksel olarak anlamlı fark bulunmamıştır.

Clostridium difficile etkenli ishal oluşumunda en önemli risk faktörü antibiyotik kullanımıdır. Tüm antibiyotikler hastalığın gelişiminde etkili olmakla beraber, Clostridium difficile ile ilişkili diyare ve kolit sıklıkla ampisilin, amoksisilin, sefalosporinler ve klindamisin gibi antibiyotiklerle ilişkilidir (18). Ercis ve ark. Clostridium difficile etkenli ishalin hastaların büyük bir kısmında (32/68) beta laktam-beta laktamaz inhibitörü antibiyotik kombinasyonlarının kullanımı sonucunda geliştiğini, bunu aminoglikozidlerin $(12 / 68)$ ve sefalosporinlerin (8/68) izlediğini saptamışlardır (14). Altındiş ve ark., Clostridium difficile toksin pozitif hastaların \%84,6'sının ampisilin-sulbaktam, \%7,7'sinin ise trimetoprim-sülfametoksazol ve makrolid antibiyotik kullandığını belirlemişlerdir (19). Altuğlu ve ark. toksin A pozitif bulunan hastaların beşinin üçüncü kuşak sefalosporin, birinin trimetoprim-sulfametoksazol ve birinin de siprofloksasin kullanmakta olduğunu saptamışlardır (15). Avustralya’da yapılan ve Clostridium difficile ile ilişkili ishal olgularının incelendiği epidemiyolojik bir çalışmada; üçüncü kuşak sefalosporinlerin kullanımının kontrol altına alınması ile Clostridium difficile ilişkili ishal olgularının azaltılabileceği bildirilmiştir (20). Çalışmamızda diğer çalışmalara benzer şekilde Clostridium difficile toksin $\mathrm{A} / \mathrm{B}$ pozitif saptanan hastaların üçünün de beta laktam antibiyotiklerden olan sefalosporin grubu seftriakson ve karbapenem grubu meropenem tedavisi aldığı saptanmıştır.

Sonuçlarımı, hastanemizden ve bölgemizden bildirilen ilk veriler olması yönünden önemlidir. Çalışmamızda \%2,8 olarak saptanan Clostridium difficile kolonizasyon oranı düşük olarak değerlendirilmiş, ancak daha önce bölgemizde bu konuda daha önce yapılmış bir çalışma varlığı saptamadığından karşılaştırma imkanı olmamıștır. Bu konuda yapılacak araștırmalarda, farklı yöntemler kullanılarak karşılaştırmalar yapılması çok yerinde olacaktır. Ayrıca genişörneklem grupları oluşturularak incelemeler ve çok merkezli çalışmalar yapılmasının faydalı olacağı düşünülmüştür.

\section{TEŞEKKÜR}

Çalışmamızı 2015.04.01.323 protokol numaralı proje ile destekleyen Düzce Üniversitesi Bilimsel Araştırma ve Projeler Koordinatörlügü’ne teşekkür ederiz.

\section{KAYNAKLAR}

1. Bilgehan H. Gram Olumlu Sporlu Basiller. In: Klinik Mikrobiyoloji, 8. baskı. İzmir: Barış Yayınları; 1994:282311.

2. Ondedonk AB, Allen SD. Clostridium. In: Murray PR, Baron E, Pfaller MA, Tenover FC, Yolken RH (ed.), Manual of Clinical Microbiology, 6. ed. Washington DC: American Society for Microbiology; 1995:574-86.

3. Drudy D, Fanning S, Kyne L. Toxin A-negative, toxin B-positive Clostridium difficile. Int J Infect Dis. 2007;11:5-10.

4. Geric B, Rubnik M, Gerding DN, Grabnar M, Johnson S. Distribution of Clostridium difficile variant toxinotypes and strains with binary toxin genes among clinical isolates in an American hospital. J Med Microbiol. 2004;53:887-94.

5. Görenek L, Beşirbellioğlu B. Antibiyotik kullanımının diğer bir yüzü: Clostridium difficile’ye bağlı ishal. Sendrom. 1997;9(10):87-94.

6. Kiyan M. Anaerob, Gram pozitif, sporlu basiller. In: Ustaçelebi Ş (ed.), Temel ve Klinik Mikrobiyoloji. Ankara: Ankara Güneş Tip Kitabevi; 2005:623-50.

7. Taşova Y. Psödomembranöz enterokolit ve Clostridium difficile. In: Ulusoy S, Usluer G, Ünal S (ed.), Gram Pozitif Bakteri İnfeksiyonları, 2. baskı. Ankara: Bilimsel Tip Yayınevi; 2012. 453-87.

8. Hookman P, Barkin JS. Clostridium difficile associated infection, diarrhea and colitis. World J Gastroenterol. 2009;15(13):1554-80.

9. Garcia C, Samalvides F, Vidal M, Gotuzzo E, Dupont HL. Epidemiology of Clostridium difficile associated diarrhea in a Peruvian tertiary care hospital. Am J Trop Med Hyg. 2007;77(5):802-5.

10. Güzel Tunçcan Ö, Ulutan F, Karakuş R. Antibiyotiğe bağlı ishal gelișen nötropenik ve nötropenik olmayan hastalarda Clostridium difficile toksin sıklığı ve risk faktörlerinin analizi. Mikrobiyol Bul. 2008;42(4); 573-83.

11. Deniz U, Ülger N, Aksu B, Karavuş M, Söyletir G. Marmara Üniversitesi Hastanesinde yatan ishalli hastalardan izole edilen Clostridium difficile kökenlerinde toksin genlerinin araştırılması. Mikrobiyol Bul. 2011;45(1):1- 
10.

12. Ju Lin H, Pin Hung Y, Chuan Liu H, Chieh Lee J, I Lee C, Hui Wu Y ve ark. Risk factors for Clostridium difficileassociated diarrhea among hospitalized adults with fecal toxigenic C. difficile colonization. J Microbiol Immunol Infect. 2015;48(2):183-9.

13. Barbut F, Petit JC. Epidemiology of Clostridium difficile associated infections. Clin Microbiol Infect. 2001;7(8):405-10.

14. Ercis S, Ergin A, Hasçelik G. Clostridium difficile’ye bağ$l_{1}$ ishal olgularının 6 yıllık değerlendirilmesi. Mikrobiyol Bul. 2004;38(1-2):45-50.

15. Altuğlu İ, Aydemir Ş, Zeytinoğlu A, Erensoy S, Bilgiç A. Antibiyotikle ilişkili nozokomiyal diyarelerde Clostridium difficile toksin A araştırılması. Turkish J Infect. 2001;15(4):495-7.

16. Loo VG, Bourgault AM, Poirier L, Lamothe F, Michaud S, Turgeon N ve ark. Host and pathogen factors for Clostridium difficile infection and colonization. N Engl J Med. 2011;365:1693-703.
17. Nissle K, Kopf D, Rösler A. Asymptomatic and yet Clostridium difficile-toxin positive? Prevalence and risk factors of carriers of toxigenic Clostridium difficile among geriatric in-patients. BMC Geriatrics. 2016;16:185.

18. Kelly CP, LaMont JT. Clostridium difficile infection. Annu Rev Med. 1998;49:375-90.

19. Altındiş M, Usluer S, Çiftçi İH, Tunç N, Çetinkaya Z, Aktepe OC. Antibiyotiğe bağlı ishal olgularında Clostridium difficile varlığının kültür ve toksin saptama yöntemleriyle araştırılması. Mikrobiyol Bul. 2007;41(1):29-37.

20. Thomas C, Stevenson M, Williamson DJ, Riley TV. Clostridium difficile-associated diarrhea: epidemiological data from Western Australia associated with a modified antibiotic policy. Clin Infect Dis. 2002;35(12):1457-62. 